of the scientific investigator, but of the medieval theologian appealing to the emotions in defence of some dogma which is indefensible by reason.

G. Elliot Smith.

The University, Manchester.

\section{The Board of Education and Laboratory Work: A Correction.}

ON p. 548 of Nature (January i3) I stated that the Board of Education had suggested the substitution of lecture-demonstrations for laboratory work in schools. I have been informed that the apparently trustworthy information on which I relied was incorrect. It is satisfactory to be able to state authoritatively that the Board has made no such suggestion, nor was the Board responsible for the recent adoption of this form of retrenchment in certain schools.

\section{G. F. Daniell.}

\section{A TERRESTRIAL CRATER OF THE LUNAR TYPE. ${ }^{1}$}

$A$ LTHOUGH the memoir before us was read before the U.S. National Academy of Sciences so far back as six years ago, it has only stone (carboniferous), and roooft. of white sandstone. Although these beds underlying the "butte" have been explored by numerous borings, neither in the strata themselves nor in the dark red sandstone rocks below them has the smallest indication of volcanic materials been met with; neither has the faintest trace of solfataric or other volcanic action been detected. The nearest scene of volcanic activity is found on a small scale nine miles away, and on a grander scale 40 miles farther. On the other hand, fragments of the famous "Canyon Diablo meteorite" (which contains diamonds with platinum and iridium) have been found in countless numbers in and around the "butte," and up to a distance of five miles around it.

The "crater" of Coon Butte is a depression, circular in form and about $4000 \mathrm{ft}$. in diameter, with a rim that rises $570 \mathrm{ft}$. above a floor, which is quite level except where obscured by talus from the rim. In this rim the limestone and sandstone rocks are seen to have undergone the most violent disturbance; they dip away from the centre at various angles up to $90^{\circ}$. For distances up to

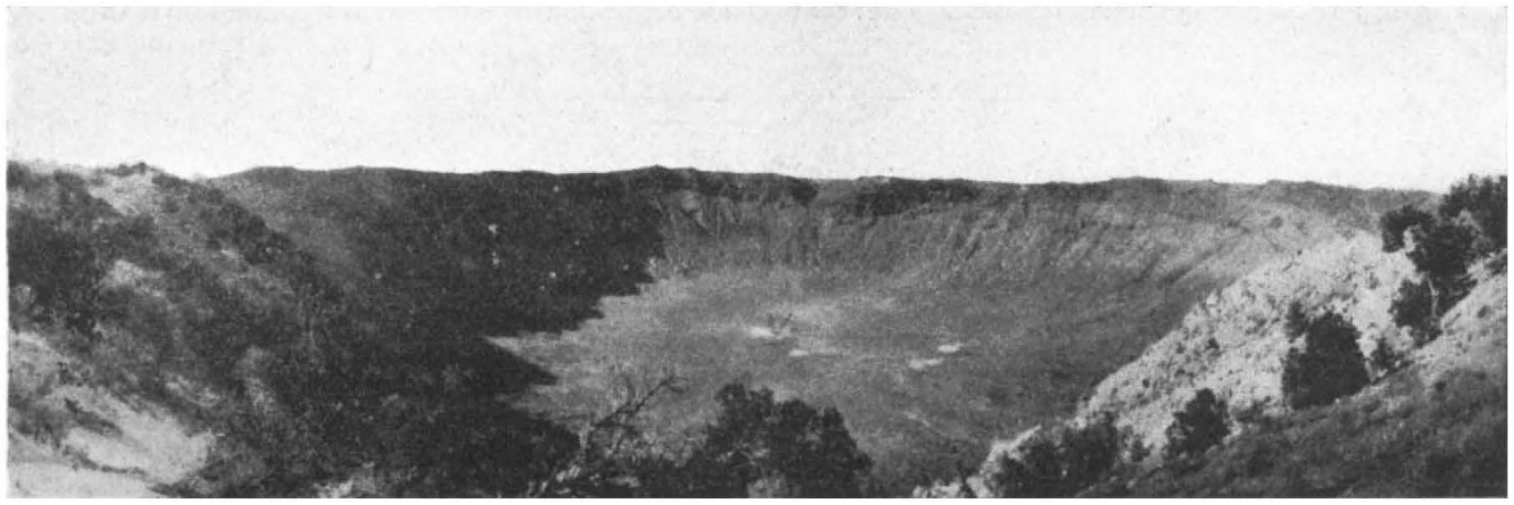

FiG. 1.-Interior view of crater, looking N.N.W.

recently been received, and it must always be regarded as a chief source of our information concerning one of the most striking features presented anywhere on the earth's surface. The author, who was one of the firm which obtained possession of the locality, has accumulated by persistent and accurate observation such a wealth of valuable information that his memoir will always remain of the highest scientific value.

Among the interesting phenomena revealed by the exploration of the western territories of the United States, none yield in importance to the remarkable ringed depression which received the name of "Coon Butte." Situated 7o miles from the famous Grand Canyon of the Colorado, and only $2 \frac{1}{2}$ miles from the Canyon Diablo, with its innumerable scattered meteorites, the strata underlying all three localities are the same and are perfectly horizontal. These well-known strata consist of 40 or $50 \mathrm{ft}$. of purplish-red sandstone, underlain successively by 250 to $300 \mathrm{ft}$. of lime-

1 "Meteor Crater (formerly called Coon Mountain or Coon Butte) in Northern Central Arizona." By D. M. Barringer. Paper read before the U.S. National Academy of Sciences.

NO. 24I3, VOL. 96] two miles from the "butte" ejected fragments of the strata are found, those of the limestone being great angular blocks up to thousands of tons in weight, while the sandstone is usually finely divided and often in a completely pulverised condition. The minute study of the ejected sandstones shows evidence of their having been subjected to most intense mechanical forces. In many cases the individual sand-grains are pulverised into a fine "silica-meal "; where, as generally happens, the original bedding planes are visible, they are seen to have been bent and twisted in the most striking manner, and in some cases a lamination cutting across the bedding planes has been induced strikingly similar to the cleavage of slaty rocks. More rarely fusion of the silica has taken place, and portions of the original sandgrains are involved in chalcedony, a pumice-like material being formed which floats in water.

Scattered among the other ejected fragments as well as in the "butte" itself are numerous examples of what the author calls "shale-balls," by others, perhaps more appropriately, designated 
"iron-shale." They are rounded or globular in form but never angular, and have the same "shaly" appearance as some of the sandstone fragments. On examination they prove to be oxidised masses of nickel-iron, and in some cases, in spite of their alteration, the Widmanstätten figures may be clearly recognised in them; they sometimes contain nuclei of unaltered nickel-iron. The larger of the well-known Canyon Diablo meteorites, which are of weights up to 300 or even rooo lb., show no trace of alteration, but exhibit the pitted surfaces and other features of independent meteorites. Thus it would appear that at this locality there were two types of meteorites, one very easily acted upon by oxidation, and it is possible that some of the smaller "Canyon Diablo meteorites" may be only nuclei of the oxidisable variety.

All the American geologists who have studied the locality are in agreement as to the non-volcanic origin of this "crater"; Prof. G. K. Gilbert, however, has suggested a theory which has found wide acceptance. It is that the "crater" is due to the impact of a great meteorite or group of meteorites, which has produced the violent mechanical effects everywhere visible. The only drive before it a "wad" of air capable of crushing out the great circular cavity, while this same air, in its upward escape, would effect the upheaval of the rocks of the rim and the ejection of materials to distances up to two miles from it. The problem of the existence of the great meteorite at considerable depths or its gradual disappearance by oxidation still remains.

It is evident that the striking characters of this singular "crater" are of no less interest to astronomers - so suggestive are the characters in which it agrees with the vast lunar craters-than to geologists, who up to the present have been chiefly attracted by the phenomenon.

\section{RECENT PUBLICATIONS OF THE CAPE OBSERVATORY.'}

A LTHOUGH Sir David Gill retired from the A direction of the Cape Observatory early in I907, and died just seven years later, the volumes from that observatory which have recently been distributed are essentially his work. Even in the contributions of successor and collaborator Gill's inspiration and design are evident. It is not too much to say that the same spirit of energy

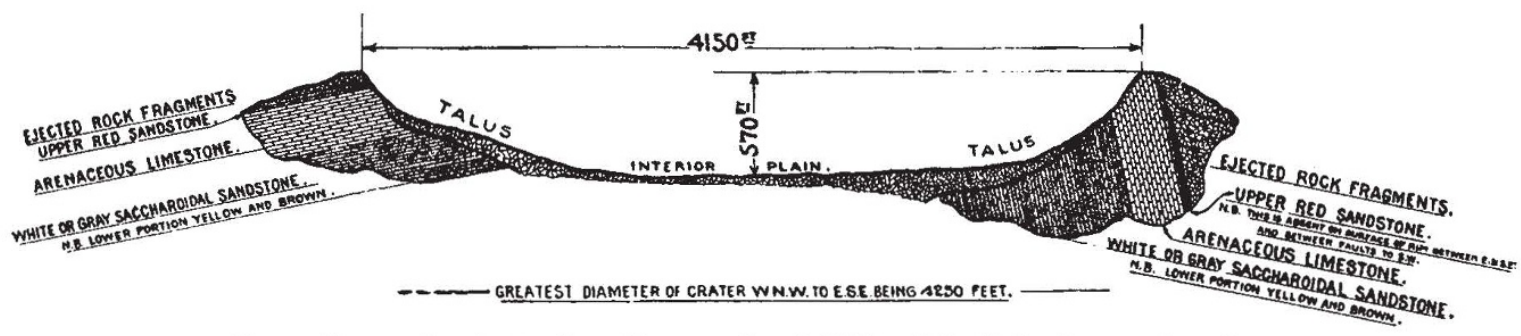

Fic. 2. - Cross-section of crater along a line approximately N.W. to S.E. Scale, about $1290 \mathrm{ft} .=1$ in.

analogous case that can be cited-and it is a rather remote one-is that of the meteorite of Knyahinya in Hungary, which weighed $660 \mathrm{lb}$, and, according to Haidinger, buried itself when it fell in I866 to the depth of $\mathrm{I} 7 \mathrm{ft}$., forming a circular pit $4 \mathrm{ft}$. in diameter and $4 \frac{1}{2} \mathrm{ft}$. deep. Coon Butte may not unnaturally be accepted as supplying a very suggestive explanation of the origin of the far larger lunar craters which present so many features in common with it.

It must be confessed, however, that many unsolved difficulties remain to prevent our unhesitating acceptance of the meteoric theory. Chief among these is the question of what has become of the vast mass of matter capable of producing the shattering impact. Only scattered fragments of nickel-iron have been detected at the depths reached by the borings, and the existence of a vast mass of meteoric iron at greater depths finds no confirmation from the magnetic observations carried on in and around the "butte." In an appendix to the memoir an account is given of a striking suggestion on the subject by Prof. H. N. Russell. He argues that a great meteorite or group of meteorites, moving with planetary velocities, would, on reaching our atmosphere, and thoroughness will endure in the pages of future publications long after his name has disappeared from the title. No greater tribute can be paid to the memory of a great man. His personal achievement was considerable, but beyond that his influence on others will surely live.

These three volumes are typical of the three main currents to be observed in Gill's purely astronomical work. There is a zone of the Cape Astrographic Catalogue, a contribution to the great scheme of registering the positions of the stars by photography, with the inception and execution of which Gill was so largely identified. There is a volume of meridian work dealing both with the old transit circle and the new instru-

1 Cape Astrographic Zones. Vol. ii.. Catalogue of Rectangular Co. ordinates and Diameters of Star-Images derived from Photographs taken at the Royal (Observatory, Cape of Good Hope, commenced under the direction of Sir David Gill, completed and prepared for press under the supervision of S. S. Hough. Zone $-42^{\circ}$. (Edinburgh: H.M.S.O. ; London: Wyman and Sons, Ltd., xor 4.) Price $20 s$.

Results of Meridian Observations of Stars made at the Royal Observatory, Cape of Good Hope, in the Years 1905 to 1908 , under the direction of Sir David Gill and S. S. Hongh. (Edinburgh: H.M.S.O.; London : Wyman and Sons, Ltd., rgr4.) Price $30 s$.

Annals of the Cape Observatory. Vol, xii, Part i. Determination of the Mass of Jupiter and Elements of the Orbits of its Satellites from Observations made with the Cape Helioneter by Sir David Gill and W. H. tions made with the Cape Helioneter by Sir David Gill and W. H.

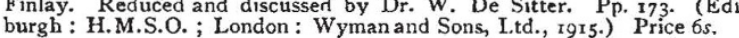
NO. 24I3, vOL. 96] 